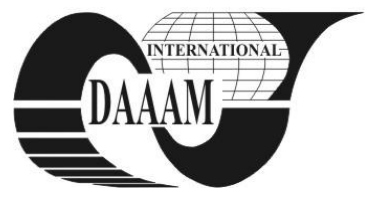

Annals of DAAAM for 2011 \& Proceedings of the 22nd International DAAAM Symposium, Volume 22, No. 1, ISSN 1726-9679 ISBN 978-3-901509-83-4, Editor B. Katalinic, Published by DAAAM International, Vienna, Austria, EU, 2011 Make Harmony between Technology and Nature, and Your Mind will Fly Free as a Bird Annals \& Proceedings of DAAAM International 2011

\title{
VISUALIZATION OF OVERLAPPING OF SCANNED AREAS AT MEAN RADIANT TEMPERATURE MEASUREMENT
}

\author{
PALKA, J[iri]
}

\begin{abstract}
This contribution deals with visualization of overlapping of scanned areas at mean radiant temperature (MRT) measurement. Mean radiant temperature is parameter used in thermal comfort determination and has the strongest influence on thermophysiological comfort indices (e.g. Predicted Mean Vote index) (Auliciems, 2007). Our solution uses thermopiles instead of globe thermometer that is usually used. We use the thermopiles because of known globe thermometer problems in MRT measurements like disability to measure asymmetric radiation, high time constant and other. Thermopile sensor scans particular angle with output signal depending on angle of incidence. This article shows how well is the whole scanned area covered and if any blind spaces exist Key words: MRT, mean radiant temperature, thermal comfort, thermopile
\end{abstract}

\section{INTRODUCTION}

This contribution deals with vizualization of overlapping of scanned areas in mean radiant temperature measurement (MRT) measurement. Mean radiant temperature is parameter used in thermal comfort determination and has the strongest influence on thermophysiological comfort indexes, e.g. Predicted Mean Vote index (Fanger, 1973). It is simply the area weighted mean temperature of all the objects surrounding the body (ISO 7730, 2005). Usually, the MRT is measured with a globe thermometer, that is dry bulb thermometer inserted in matte-black copper sphere with $150 \mathrm{~mm}$ diameter and absorptivity that is close to the skin absorptivity (ISO 7726, 1998).

Globe themometer has known problems influencing the MRT measurements. These shortcomings are:
a) air speed,
b) influence of ambient temperature,
c) impossibility to assess asymetric thermal radiation,
d) high time constant.

The cases c) and d) were also described in (Hruška, 2003). Hruška did analysis of globe thermometer in COMSOL Multiphysics (formerly FEMLAB) and also experimentally verified. COMSOL Multiphysics is an engineering, design and finite element analysis software environment for the modeling and simulation of any physics-based system.

This new solution deals with measurement of mean radiant temperature with thermopile sensors. The thermopile is an electronic device that converts thermal energy into electrical energy, de facto into electrical signal. Basic concept of this device is based on thermocouples connected in series to increase the output voltage. Output signal corresponding to the object temperature that we measure is independent on air speed and ambient temperature (Schilz, 2000). The time constant of this sensor is tens of milliseconds (globe thermometer hase hundreds of seconds). Finally; it is possible to measure the asymmetric thermal radiation.

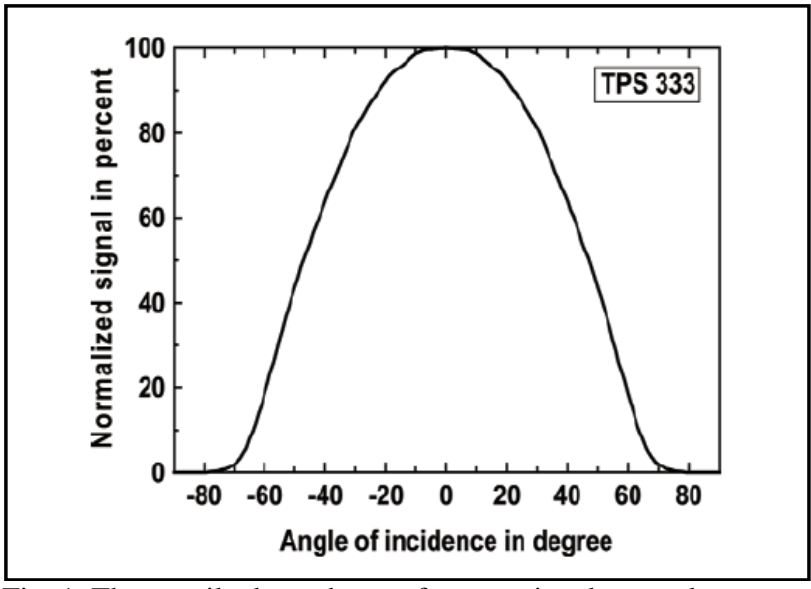

Fig. 1. Thermopile dependence of output signal on angle

\section{DESIGNED SOLUTION}

The thermopile sensor scans particular angle (Field of View $(\mathrm{FOV})$ ) and its output signal depends incident radiation and also on angle of incidence. Our solution uses 6 thermopile sensors (basic concept) to scan complete full space, i.e. $2 \pi$ radians. We have chosen TPS333 thermopile sensor from Perkin Elmer company, equipped with a $5.5 \mu \mathrm{m}$ longpass (standard) infrared filter. The detector shows a constant sensitivity characteristics over the wavelength and has $100^{\circ}$ field of view at $50 \%$ of normalized signal (see Fig. 1). (www.perkinelmer.com, 2010). With this constitution we are also able to assess each direction independently, evaluate the asymetric thermal radiation and its influence on thermal comfort. The location of all sensors and scanned direction is shown on Fig. 2. and with this we should scan the full space. We will decide if this presumption is true with visualization of overlapping of scanned areas by each thermopile.

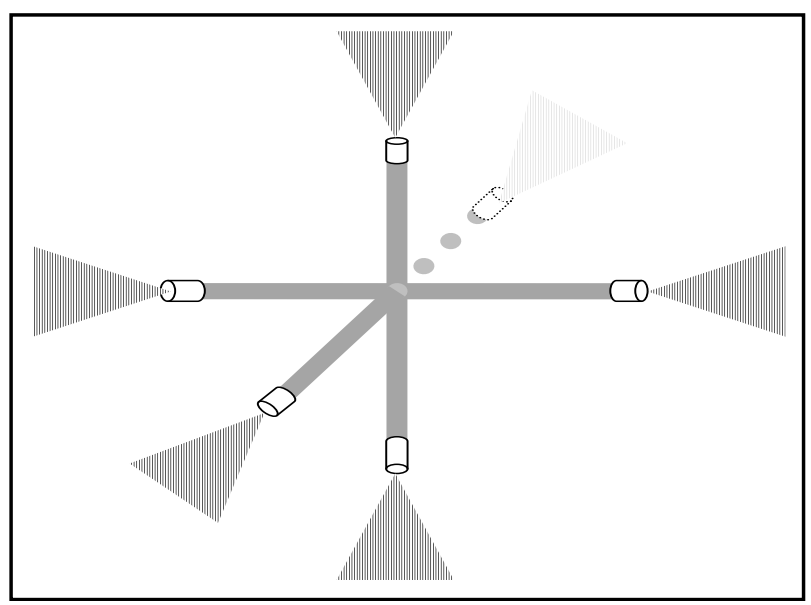

Fig. 2. The sensors location 


\section{VISUALIZATION OF OVERLAPPING OF SCANNED AREAS}

We decided to visualize the overlapping of scanned areas in MATLAB software. First of all, we described the thermopile dependence of output signal on angle by equation. The basic principle is to describe this dependency (Fig. 1) by mathematical equation. The normalized signal can be manually described by set of pairs (angle, normalized signal) and then this dependency is converted into mathematical formula with matlab script using lsqcurfit function that provides data-fitting base on least-squares method. The script that ensures datafitting and displays found function is described by following commands:

$$
\begin{aligned}
& \text { [var]=load('data.txt','-ascii'); } \\
& \text { angle=var(:,1); } \\
& \mathrm{f}=\mathrm{var}(:, 2) ; \\
& \mathrm{x} 0=[4 \mathrm{e}-7,0.1,-90] \quad \% \text { initial assessment } \\
& {[\mathrm{x}, \text { resnorm }]=1 \text { sqcurvefit }(@ \text { myfun,x0,angle,f); }} \\
& \mathrm{a}=\mathrm{x}(1) \% \text { coefficient } \\
& \mathrm{b}=\mathrm{x}(2) \% \text { coefficient } \\
& \mathrm{c}=\mathrm{x}(3) \% \text { coefficient }
\end{aligned}
$$

plot(angle,f,'b.'); \% show original data

hold on;

angle=-90:0.1:0;

$\mathrm{F}=1 . /(1+\mathrm{a} * \exp (-\mathrm{b} *($ angle $+\mathrm{c})))$

plot(angle,F,'r'); \% show found function

The preview of found function is displayd on Fig. 3.

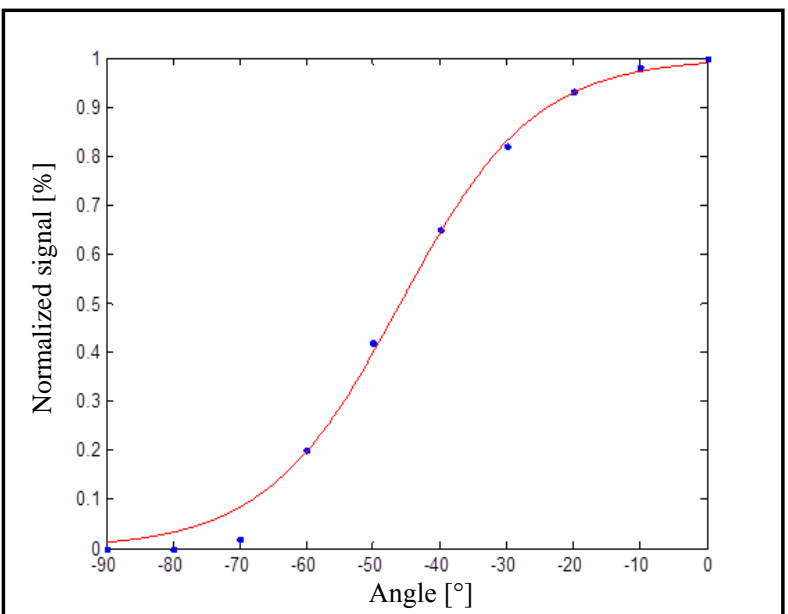

Fig. 3 Mathematical function of dependence of output signal on angle

Next, we had to transform FOV of each sensor from spherical coordinate system into Cartesian coordinates. In transformation we used equations:

$$
\begin{aligned}
& x=r \sin (\theta) \cos (\varphi) \\
& y=r \sin (\theta) \sin (\varphi) \\
& z=r \cos (\varphi)
\end{aligned}
$$

where

$\varphi$ is inclination $\left[{ }^{\circ}\right]$

$\theta$ is azimuth $\left[{ }^{\circ}\right]$

$\mathrm{x}, \mathrm{y}, \mathrm{z}$ are Cartesian coordinates

With this transformation and with mathematical description of dependence of thermopile output signal on angle we have described six sensors in space and computed normalized signal of whole 6-sensor system.

The resulting normalized signal is given as a sum of normalized signals of all thermopile sensors. The visualization of overlapping areas is shown on Fig. 4. where the colour describes the normalized signal. The colour bar is also presented on figure with red colour closed to $100 \%$. As can be seen; the 6-sensor system contains spaces where the incident radiation is detected insufficiently and this concept should be improved with changing number of sensors or with the changing of field of view shape.

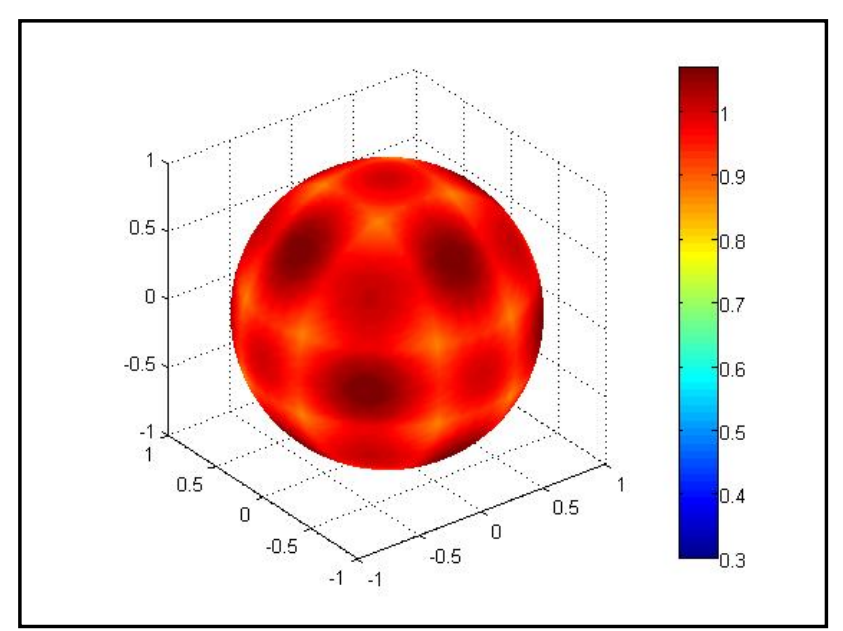

Fig. 4. Overlapping FOV of sensors

\section{CONCLUSION}

With this research we are able to visualize and evaluate the total FOV of all sensors used in mean radiant temperature evaluation. Matlab scripts are prepared to work with different sensors, especially with different FOV and also with various numbers of sensors.

The major task of this research is to design system that scans whole area and visualize the overlapping areas and helps to find the constitution giving uniformly distributed normalized signal and therefore more precise mean radiant temperature and thermal comfort index measurement.

\section{REFERENCES}

Auliciems, Andris and Szokolay, Steven V. (2007). Thermal Comfort. The University of Queensland. ISBN 086776729 4.

Fanger , P. O. (1973) Thermal Comfort. McGraw-Hill, New York, ISBN: 978-0070199156

ISO 7730 (2005) Ergonomics of the thermal environment Analytical determination and interpretation of thermal comfort using calculation of the PMV and PPD indices and local thermal comfort criteria. International standard.

ISO 7726 (1998) Ergonomics of the thermal environment Instruments for measuring. International standard.

Hruska, F. (2003) Measurement of mean radiant temperature for thermal comfort indexes assessment. Habilitation thesis. Tomas Bata University in Zlin

Schilz, J. (2000) Thermophysica minima: applications of thermoelectric infrared sensors (thermopiles): gas detection by infrared absorption. NDIR, PerkinElmer Optoelectronics

*** (2010) http://www.perkinelmer.com - TPS 333 Thermopile detector datasheet. Accesed on 2010-07-01 